\title{
Small cell glioblastoma multiforme: a case series and clinicopathological update
}

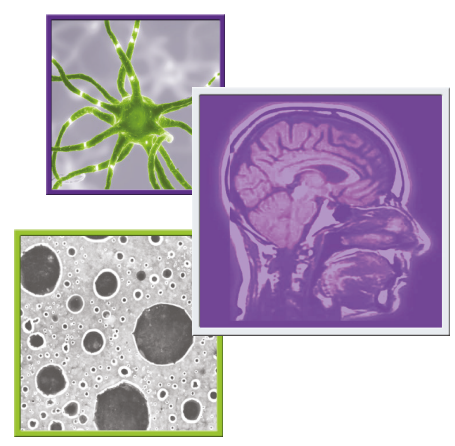

\author{
Arun Kumar Yadav", Renu Madan*,1(D), Debajyoti Chatterjee², Shalin Dhiman¹, Shikha \\ Goyal $^{1}$, Narendra Kumar ${ }^{1}$ \& Sushanta Kumar Sahoo ${ }^{3}$ \\ ${ }^{1}$ Department of Radiotherapy \& Oncology, Postgraduate Institute of Medical Education \& Research, Chandigarh 160012, India \\ ${ }^{2}$ Department of Histopathology, Postgraduate Institute of Medical Education \& Research, Chandigarh 160012, India \\ ${ }^{3}$ Department of Neurosurgery, Postgraduate Institute of Medical Education \& Research, Chandigarh 160012, India \\ *Author for correspondence: renumadan10@yahoo.com
}

Small cell glioblastoma (scGBM) is a rare histological variant of classical glioblastoma (GBM). Presence of necrosis and microvascular proliferation is not essential for the diagnosis. It is thought to have more aggressive behavior as compared with classical GBM; however, because of its rarity standard treatment guidelines are not available. Adjuvant treatment for these cancers consists of postoperative radiotherapy with concurrent and maintenance temozolomide similar to classical GBM. Here we present a case series of five small cell glioblastoma patients along with the clinical-pathological review.

\section{Graphical abstract:}

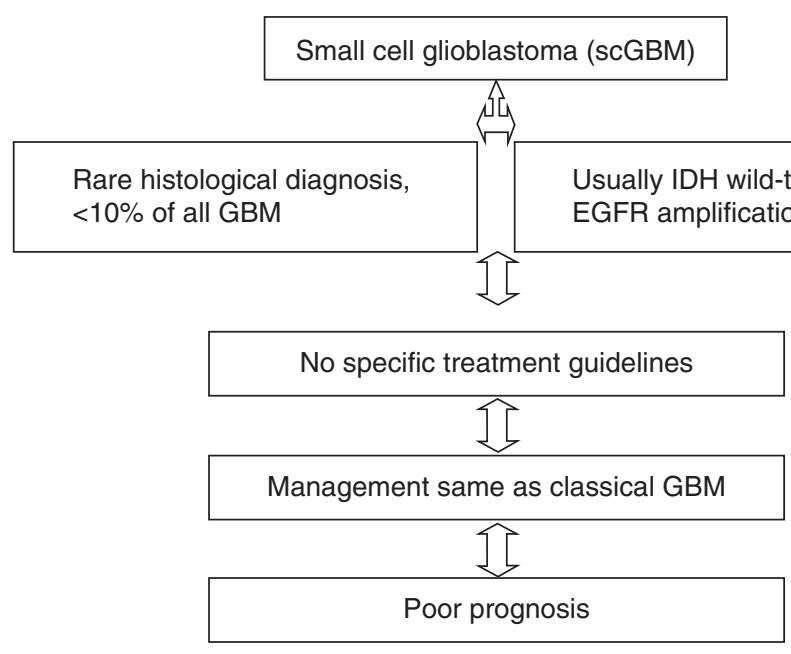

First draft submitted: 17 June 2020; Accepted for publication: 3 September 2020; Published online:

7 December 2020

Keywords: concurrent chemotherapy $\bullet$ glioblastoma multiforme $\bullet$ glioma $\bullet$ high grade $\bullet$ immunohistochemistry $\bullet$ pathology $\bullet$ prognosis $\bullet$ radiotherapy $\bullet$ small cell $\bullet$ temozolomide

Small cell glioblastoma (scGBM) is a rare histological variant of classical glioblastoma (GBM) and constitutes $<10 \%$ of all GBMs [1]. scGBM is usually IDH wild type and shows EGFR amplification. Owing to its rarity, clinical behavior and specific treatment guidelines are not available. Previous reports have suggested that it has an aggressive behavior as compared with classical GBM.

Most patients receive treatment on the same protocols as classical GBM. However, it's aggressive nature and different molecular profile suggest a need to explore methods of treatment intensification with either radiotherapy (RT) or targeted therapy. Here we present a case series of five scGBM patients along with clinical-pathological review, differential diagnosis and outcome. 


\section{Case series}

Radiotherapy records from the past year were reviewed to identify scGBM patients for analysis. Clinicopathological, demographic, treatment and survival details were entered in a predesigned proforma.

\section{Case 1}

A 56-year old male presented with headache and altered sensorium. Contrast enhanced MRI (CEMRI) of the brain showed features of high-grade glioma (HGG) in the right temporal lobe. He underwent craniotomy with subtotal excision of tumor. He received 20 fractions of RT with temozolomide (TMZ) and later defaulted for further radiotherapy. He was on the best available supportive care at nearby government hospital and died 6 months after diagnosis.

\section{Case 2}

A 57-year old male patient presented with headache, vomiting and right sided weakness. CEMRI brain showed HGG in the left temporoparietal lobe for which he underwent craniotomy and gross total excision of the tumor. He did not seek any adjuvant chemoradiation due to SARS-CoV-2 related lockdown and was on domiciliary care. Later, his health deteriorated and he died 5 months post diagnosis.

\section{Case 3}

A 62-year old male patient presented with headache. CEMRI of the brain revealed multicentric lesions for which he underwent craniotomy and subtotal excision of the tumor. He has completed postoperative RT (PORT) with concurrent TMZ. Currently he is on adjuvant TMZ and has received four cycles of TMZ to date. Patient is asymptomatic at present.

\section{Case 4}

A 53-year old male patient presented with headache, nausea and memory disturbance. CEMRI of the brain showed HGG in the left temporoparietal region. He underwent gross total excision of the tumor, but his adjuvant treatment was compromised due to SARS-CoV-2 related travel disruptions. His performance status deteriorated and he died 4 months after his diagnosis.

\section{Case 5}

A 36-year old female presented with headache and vomiting. CEMRI of the brain showed a frontal lesion for which she underwent craniotomy and subtotal excision. She could not make her visits to hospital for adjuvant treatment amidst SARS-CoV-2 related lockdown and died 3 months after her diagnosis.

\section{Histopathological examination}

Histopathological examination of all cases showed features of HGG. They were composed of sheets of neoplastic glial cells in a fibrillary background. The cells varied from round to elongated, with high nuclear:cytoplasmic ratio and hyperchromatic nuclei. They showed high mitotic and apoptotic activity. High-grade features, such as necrosis and microvascular proliferation, were present in all. Case 2 showed extensive necrosis with predominantly perivascular preservation of tumor cells. Case 3 and 4 showed focal perinuclear halo and delicate capillary network (Figure 1). Rosette formation could not be appreciated in any case.

On performing immunohistochemistry, all cases showed patchy positivity for GFAP and synaptophysin (Figure $2 \mathrm{~A} \& \mathrm{~B}$ ). CD56 showed membranous staining in one case (Figure 2C). They were negative for cytokeratin, TTF1, CD45, CD3, CD20, neurofilament protein and NeuN. All cases were negative for IDH1R132H (Dianova, clone H09) (Figure 2D) and showed retained nuclear ATRX expression. Ki-67 index was uniformly high in all. All cases were negative for $p 53$. FISH was carried out for $1 \mathrm{p} / 19 \mathrm{q}$ codeletion using dual color probe (Vysis), all cases found be negative. EGFR immunopositivity was detected in two cases (40\%, cases 2 and 5); however, EGFR amplification by FISH could not be carried out. Thus, these cases were diagnosed as scGBM, grade IV (WHO, 2016).

Table 1 shows clinicopathological and survival details of all five scGBM patients.

Table 2 shows differential diagnosis of scGBM based on immunohistochemistry. 
Table 1. Clinicopathological and survival details of small cell glioblastoma patients.

\begin{tabular}{|c|c|c|c|c|c|c|}
\hline & & Patient 1 & Patient 2 & Patient 3 & Patient 4 & Patient 5 \\
\hline Age (years)/sex & & $56 /$ male & $57 /$ male & $62 /$ male & $53 /$ male & $36 /$ female \\
\hline \multirow[t]{4}{*}{ Clinical presentation } & $\begin{array}{l}\text { Features of raised } \\
\text { intracranial tension }\end{array}$ & Headache & $\begin{array}{l}\text { Headache and } \\
\text { vomiting }\end{array}$ & Headache & Headache and nausea & Headache and vomiting \\
\hline & Neurological deficit & - & Right sided weakness & - & - & - \\
\hline & Sensorium & Altered & - & - & - & - \\
\hline & Memory & - & - & - & Impaired & - \\
\hline $\begin{array}{l}\text { Duration of } \\
\text { symptoms }\end{array}$ & & 3 weeks & 10 days & 1 month & 15 days & 3 months \\
\hline $\begin{array}{l}\text { Karnofsky } \\
\text { performance status } \\
\text { (KPS) }\end{array}$ & & 70 & 70 & 80 & 60 & 60 \\
\hline \multirow[t]{5}{*}{ MRI (pre-operation) } & Site & Right temporal lobe & $\begin{array}{l}\text { Left parieto-occipital } \\
\text { lobe }\end{array}$ & $\begin{array}{l}\text { Left frontal parietal, } \\
\text { temporal and } \\
\text { occipital lobe }\end{array}$ & $\begin{array}{l}\text { Left parietal and } \\
\text { occipital lobe }\end{array}$ & Left temporal lobe \\
\hline & Focality & Solitary & Solitary & Multifocal & Multifocal & Solitary \\
\hline & Size $(\mathrm{cm})$ & $7.5 \times 6 \times 5.6$ & $5.6 \times 7 \times 4$ & $\begin{array}{l}7.3 \times 4.7 \times 5.9,2.6 \times \\
2.9 \times 2.9 \& 2 \times 1.6 \times \\
1\end{array}$ & $\begin{array}{l}5.4 \times 2.7 \times 4.1 \& 4.5 \\
\times 3.6 \times 2.8\end{array}$ & $10.3 \times 6.7 \times 4.6$ \\
\hline & $\begin{array}{l}\text { Postcontrast } \\
\text { enhancement }\end{array}$ & Absent & Present & Present & Present & Present \\
\hline & $\begin{array}{l}\text { Perilesional edema } \\
\text { and mass effect }\end{array}$ & Absent & Present & Present & Present & Present \\
\hline Type of surgery & & STE & GTE & GTE & GTE & GTE \\
\hline \multirow[t]{4}{*}{ Histopathology } & $\begin{array}{l}\text { Percentage of small } \\
\text { cell component }(\%)\end{array}$ & $40-50$ & $60-70$ & $40-50$ & $50-60$ & $60-70$ \\
\hline & Necrosis & Present & Present & Present & Present & Present \\
\hline & MVP & Present & Present & Present & Present & Present \\
\hline & $\begin{array}{l}\text { Lymphocytic } \\
\text { infiltration }\end{array}$ & Negative & Negative & Negative & Negative & Negative \\
\hline \multirow{7}{*}{$\begin{array}{l}\text { Immuno-histo- } \\
\text { chemistry }\end{array}$} & IDH1R132H mutation & Negative & Negative & Negative & Negative & Negative \\
\hline & $\operatorname{ATRX}$ & Retained & Retained & Retained & Retained & Retained \\
\hline & p53 mutation & Negative & Negative & Negative & Negative & Negative \\
\hline & Ki-67 & High & High & High & High & High \\
\hline & $1 p / 19 q$ codeletion & Negative & Negative & Negative & Negative & Negative \\
\hline & EGFR amplification & Negative & Positive & Negative & Negative & Positive \\
\hline & $\begin{array}{l}\text { Cytokeratin, TTF1 } \\
\text { CD45, CD3, CD20, } \\
\text { Neurofilament } \\
\text { protein and Neu N }\end{array}$ & Negative & Negative & Negative & Negative & Negative \\
\hline $\begin{array}{l}\text { Improvement/ } \\
\text { deterioration after } \\
\text { surgery }\end{array}$ & & Improved & Improved & Improved & Improved & Improved \\
\hline PORT & & $\begin{array}{l}\text { Defaulted after } 20 \\
\text { fractions of } \\
\text { radiotherapy }\end{array}$ & Not received & $\begin{array}{l}60 \mathrm{~Gy} / 30 \text { fractions } / 6 \\
\text { weeks }\end{array}$ & Not received & Not received \\
\hline Concurrent TMZ & & Yes & - & Yes & - & - \\
\hline Adjuvant TMZ & & - & - & $\begin{array}{l}\text { Ongoing (completed } \\
4 \text { cycles) }\end{array}$ & - & - \\
\hline $\begin{array}{l}\text { MRI (after } \\
\text { radiotherapy) }\end{array}$ & & - & - & Partial response & - & - \\
\hline Survival & & $\begin{array}{l}\text { Died } 6 \text { months post } \\
\text { diagnosis }\end{array}$ & $\begin{array}{l}\text { Died } 5 \text { months post } \\
\text { diagnosis }\end{array}$ & $\begin{array}{l}\text { Alive } 8 \text { months post } \\
\text { diagnosis }\end{array}$ & $\begin{array}{l}\text { Died } 4 \text { months post } \\
\text { diagnosis }\end{array}$ & $\begin{array}{l}\text { Died } 3 \text { months post } \\
\text { diagnosis }\end{array}$ \\
\hline
\end{tabular}

GTE: Gross total excision; MVP: Microvascular proliferation; PORT: Postoperative radiotherapy; STE: Subtotal excision; TMZ: Temozolomide. 


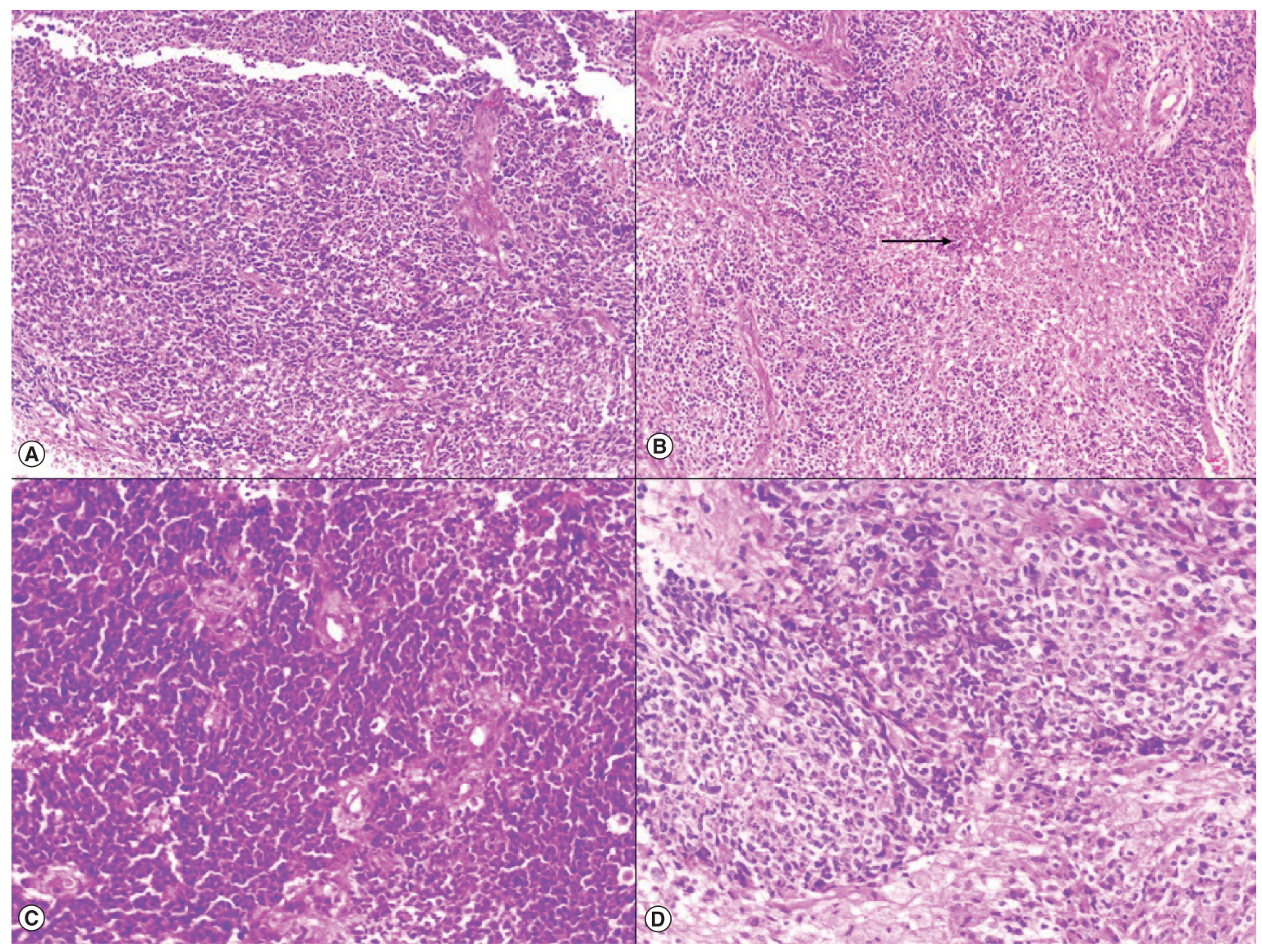

Figure 1. Histological examination. (A) Histological examination of case 1 shows a highly cellular glial tumor arranged in sheets (hematoxylin and eosin, $\times 100$ ). (B) Representative section from case 2 shows areas of palisaded necrosis, shown in black arrow (hematoxylin and eosin, $\times 100$ ). (C) Representative section from case 3 shows sheets of tumor cells with high nuclear:cytoplasmic ratio and hyperchromatic nuclei (hematoxylin and eosin, $\times 200$ ). (D) Representative section from case 4 shows focal perinuclear halo (hematoxylin and eosin, $\times 200$ ).

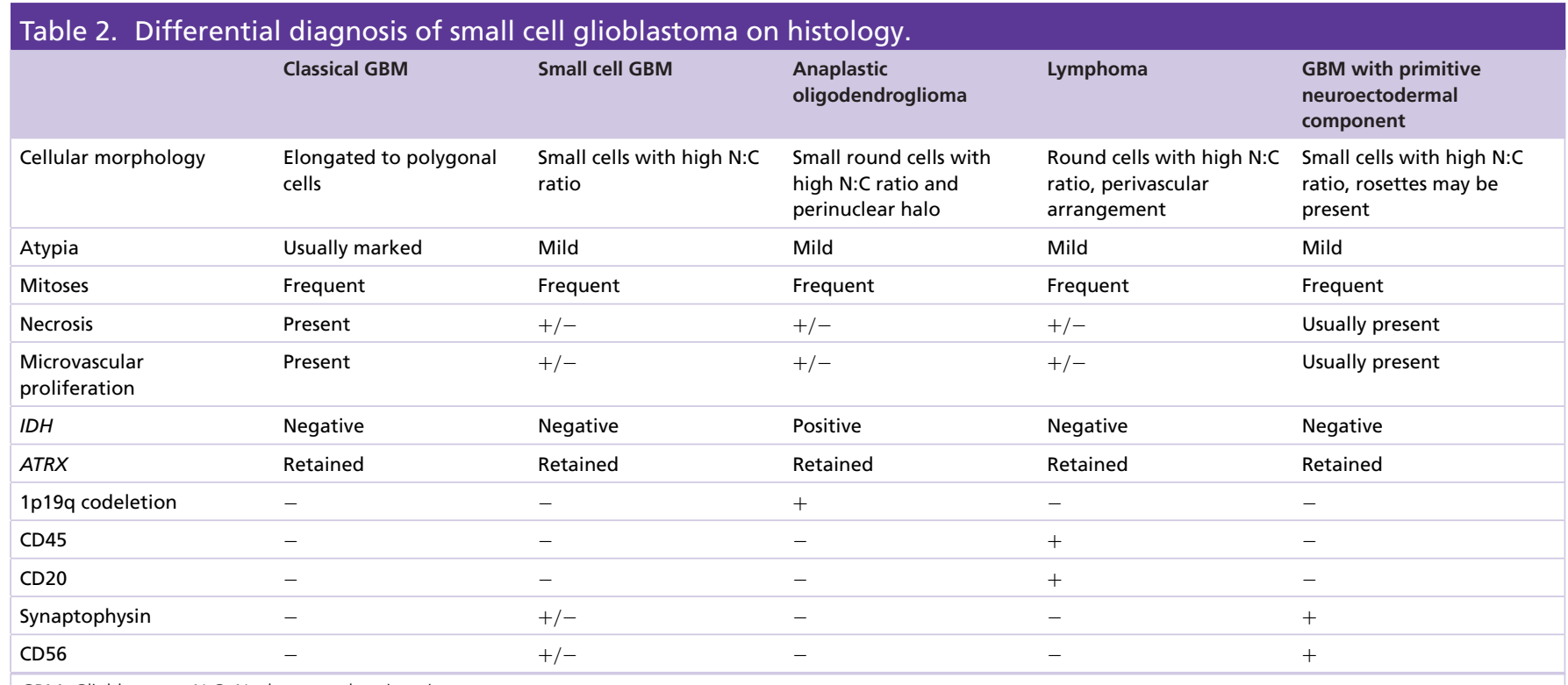

GBM: Glioblastoma; N:C: Nuclear:cytoplasmic ratio. 


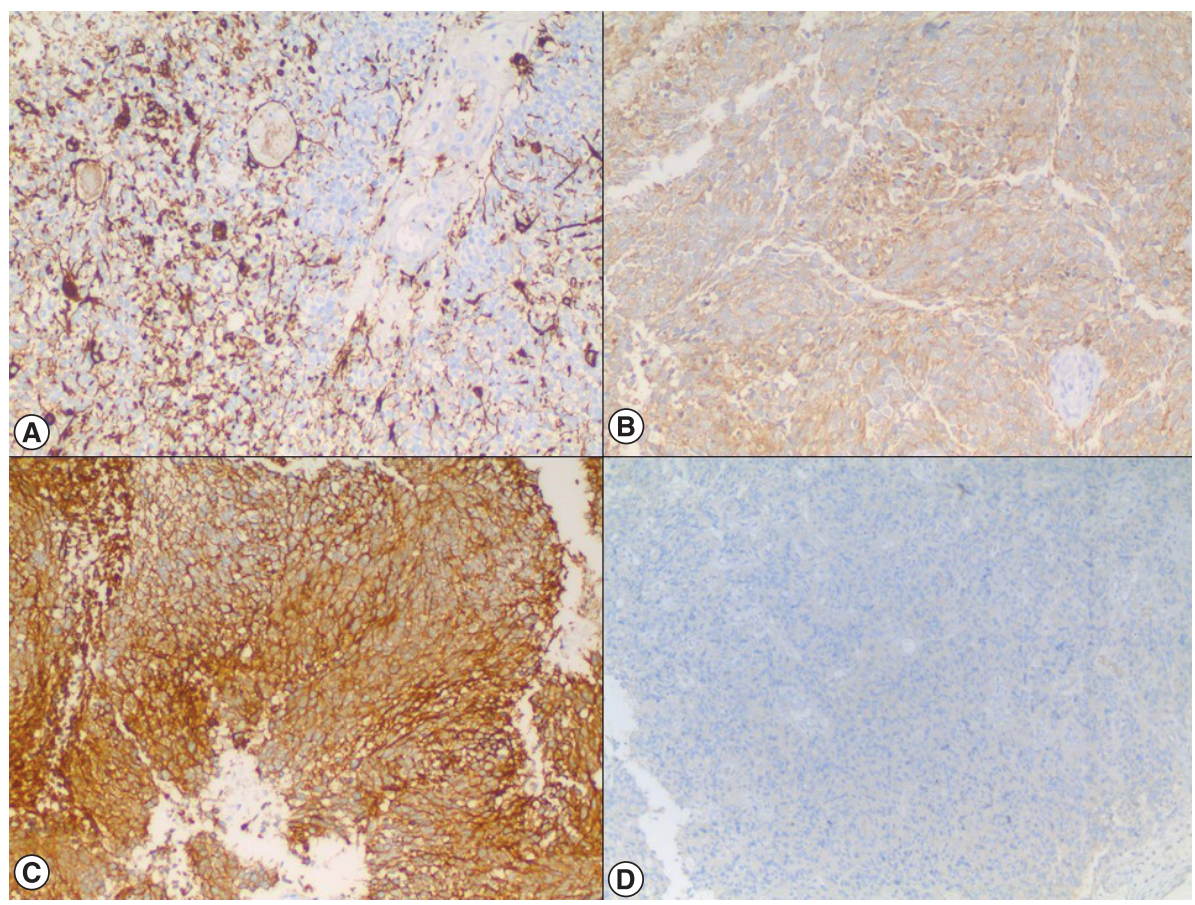

Figure 2. Immunohistochemistry. (A) Patchy strong positivity for GFAP (immunohistochemistry, $\times 100$ ). (B) Patchy and faint positivity for synaptophysin (immunohistochemistry, $\times 100$ ). (C) Diffuse membranous positivity for CD56 (immunohistochemistry, $\times 100$ ). (D) Negative for IDH1 (immunohistochemistry, $\times 100$ ).

\section{Discussion}

scGBM is rare pathological variant of classical GBM. Radiologically it does not differ from conventional GBM; however, multifocality is more common in scGBM. Morphologically, scGBM is composed of small sized astrocytes with high cellular density. The cells are round to elongated and show high nuclear cytoplasmic ratio and mitotic activity. Areas showing conventional GBM-like appearance are interspersed with predominantly small cell-like areas. There may be varying degrees of necrosis and microvascular proliferation, but these features are not essential for the diagnosis of scGBM, in contrast to conventional GBM [1]. scGBM is a diagnosis that can be certainly made only on histopathology; however, immunohistochemistry may be required to exclude differential diagnoses, including anaplastic oligodendroglioma, lymphoma, primitive neuroectodermal tumor and metastatic small cell carcinoma. FISH for $1 \mathrm{p} / 19 \mathrm{q}$ codeletion is necessary to rule out anaplastic oligodendroglioma, which is the closest differential diagnosis. All our cases were negative for IDH1 and showed retained ATRX expression.

Owing to its rarity, standard treatment guidelines are not available for scGBM and patients are treated with the same protocols as used for classical GBM. Huang et al. analyzed 281 GBM patients, of which 18 (6\%) patients had scGBM [2]. All patients received adjuvant chemoradiation including TMZ but a higher RT dose was used for scGBM, resulting in similar median survival for both groups (15.3 months for GBM and 16 months for scGBM). This led the authors to assume similar clinical outcomes [2]. Takeuchi et al. reported the clinicopathological features of $14 \mathrm{scGBM}$ patients diagnosed over a period of 10 years (2005-2015) [3]. Ten of their patients received PORT with TMZ, one patient received PORT and carboplatin-etoposide chemotherapy while three patients received only TMZ. Overall survival ranged from 5 to 23 months. No patient survived over 2 years from diagnosis, depicting aggressive behavior. In another case report, the patient received standard PORT and TMZ; however, his disease progressed after three cycles of adjuvant TMZ and he needed two more lines of chemotherapy (Irinotecan and lomustine as second line, bevacizumab and carboplatin as third line) to which he had partial response before progression [4].

Salvage options for recurrent GBM are limited. Bevacizumab has been approved for treatment of recurrent HGG and improves the steroid-free interval and progression-free survival, albeit without an impact on overall survival [5]. EGFR amplification is associated with poor response to bevacizumab in recurrent GBM [6]. As most scGBMs show EGFR amplification, the role of bevacizumab is unclear. The role of EGFR inhibitors is limited despite the patients' 
EGFR amplification as most antibodies cannot penetrate blood-brain barrier. A dull immune response in scGBM suggests the role of immunotherapy [3].

Our study has the limitation that three patients could not receive adjuvant chemoradiation due to unforeseen circumstances (SARS Cov-2 lockdown) and one patient defaulted after receiving few fractions of radiotherapy. All these four patients died within 3-6 months after diagnosis, which indicates the aggressiveness of scGBM. Only one patient who received adjuvant treatment is alive, thus highlighting the importance of chemoradiotherapy.

\title{
Conclusion
}

Small cell Gliobalstoma is an aggressive malignancy. It is a rare histological variant of classical Glioblastoma. Specific treatment guidelines are not available despite the different molecular profile as these tumors are generally not analyzed separately in clinical trials due to the rare occurrence. Inclusion of these rare histologies in clinical trials with follow-up details may help in consolidating knowledge and understanding of their clinical behavior and treatment strategies.

\section{Future perspective}

Future of GBM lies in molecular research and establishing molecular classification of predictive and prognostic markers so that patients benefit most as per there classification sub type. It would also help in evolving targeted therapy according to their molecular subtype.

\section{Executive summary}

- Small cell glioblastoma (scGBM) is a rare histological variant of glioblastoma (GBM), accounting for $<10 \%$ of all GBM cases.

- scGBM is associated with aggressive behavior and a poor outcome.

- EGFR amplification is more common for scGBM than classical GBM.

- Most of the scGBM patients are p53 negative.

- Anaplastic oligodendroglioma, lymphoma, primitive neuroectodermal tumors and metastatic small cell carcinoma of the lung are common differential diagnoses.

- Standard treatment guidelines for scGBM are unavailable.

- Most scGBMs are treated like classical GBM, with postoperative radiotherapy (60 Gy/30 fractions over 5 weeks) alongside concurrent and adjuvant temozolomide.

- Salvage options for recurrent scGBM are limited.

\begin{abstract}
Author contributions
AK Yadav: writing the manuscript, literature review; R Madan: concept, editing the manuscript, patient radiotherapy planning; D Chatterjee: provided pathology inputs; S Dhiman: did telephonic communication with the patients, spelling and grammar check; S Goyal: editing the manuscript, literature search; N Kumar: editing the manuscript; SK Sahoo: surgical inputs.
\end{abstract}

Financial \& competing interests disclosure

The authors have no relevant affiliations or financial involvement with any organization or entity with a financial interest in or financial conflict with the subject matter or materials discussed in the manuscript. This includes employment, consultancies, honoraria, stock ownership or options, expert testimony, grants or patents received or pending, or royalties.

No writing assistance was utilized in the production of this manuscript.

\section{Ethical conduct of research}

The authors state that they have obtained appropriate institutional review board approval or have followed the principles outlined in the Declaration of Helsinki for all human or animal experimental investigations. In addition, for investigations involving human subjects, informed consent has been obtained from the participants involved.

\section{Open access}

This work is licensed under the Attribution-NonCommercial-NoDerivatives 4.0 Unported License. To view a copy of this license, visit http://creativecommons.org/licenses/by-nc-nd/4.0/ 


\section{References}

Papers of special note have been highlighted as: $\bullet$ of interest; $\bullet \bullet$ of considerable interest

1. Perry A, Aldape KD, George DH, Burger PC. Small cell astrocytoma: an aggressive variant that is clinicopathologically and genetically distinct from anaplastic oligodendroglioma. Cancer 101(10), 2318-2326 (2004).

- Discusses a study that was performed to highlight the clinical, pathological features and immunohistochemistry markers of small cell component of astrocytoma and how to demarcate from its closest differential anaplastic oligodedroglioma.

2. Huang J, Badiyan SN, Cai C et al. Clinical outcomes of small cell glioblastoma or glioblastoma with oligodendroglioma component treated with radiation therapy and temozolomide. Int. J. Radiat. Oncol. Biol. Phys. 90(1), S293-S294 (2014).

- Provides an exhaustive study done on clinical outcomes of small cell glioblastoma (scGBM) and its management with concurrent chemoradiation where author has not mentioned the escalated dose but perhaps hints for higher radiotherapy dose along with concurrent temozolamide and found similar survival outcomes in regard to classical glioblastoma.

3. Takeuchi H, Kitai R, Hosoda T et al. Clinicopathologic features of small cell glioblastomas. J. Neurooncol. 127(2), 337-344 (2016).

- Beautifully depicts the various clinical and pathological findings and its corelation with scGBM. It also studied giving postoperative radiotherapy alone and various concurrent regimes, dull response to immunotherapy and conclude highlighting the aggressive behaviour of scGBM.

4. Bizu I, Georgescu M, Anghel R. Small cell glioblastoma: a glioblastoma subtype with an unexpected response. Mod. Med. 26(2), 93-96 (2019).

- Enlightens us regarding various lines of adjuvant treatment post failure to adjuvant temozolamide and its response in scGBM.

5. Taal W, Oosterkamp HM, Walenkamp AME et al. Single-agent bevacizumab or lomustine versus a combination of bevacizumab plus lomustine in patients with recurrent glioblastoma (BELOB trial): a randomised controlled Phase II trial. Lancet Oncol. 15(9), 943-953 (2014).

-• Discusses about limited salvage options available in recurrent glioblastoma multiforme and role of bevaizumab in recurrent settings.

6. Hovinga KE, McCrea HJ, Brennan C et al. EGFR amplification and classical subtype are associated with a poor response to bevacizumab in recurrent glioblastoma. J. Neurooncol. 142(2), 337-345 (2019).

-. Highlights the relation of EGFR amplification and bevacizumab response in recurrent glioblastoma multiforme. 